\title{
EXPERIENCES FROM STARTING AND RUNNING A SOFTWARE COMPANY WITHIN THE CONTEXT OF DESIGN RESEARCH
}

\author{
Bergsjö, Dag; \\ Catic, Amer \\ Chalmers University
}

\begin{abstract}
This paper deals with the story and experiences of setting up a new start-up company with the ambition to scale using a software-based product. The paper is written by researchers for researchers interested in doing the same thing. The paper concludes that it can be very beneficial for research as the startup-can be seen as a data collection machine, but to set up a start-up company, comes with unforeseen problems along the way. A few of them involves: Do not rely on rational arguments (only), when marketing your product. Expect long lead-times. Work with multiple threads and secure funding early to ensure that you can finance your startup. Finally, you need to be committed, and you have to have a strategy to manage both your research and your commercial activities.
\end{abstract}

Keywords: Market implications, Business models and considerations, User centred design

\author{
Contact: \\ Bergsjö, Dag \\ Chalmers University \\ Sweden \\ dagb@chalmers.se
}




\section{INTRODUCTION}

Many companies rely on production and development in a multitude of sites around the globe. However, this globalization has a cost where cultural barriers, communication barriers, and time zone barriers actually hinders development and leads to miscommunication, delays, and increased cost. Lean and Agile development has introduced a number of project and development methodologies that encourages direct communication that decreases miscommunication; however, the lean and agile paradigm focuses (at least in the beginning of 2012 when this research began) on direct personal communication and by using physical visual aids, typically sticky notes posted on a whiteboard or brown paper to indicate the plan, broken down to who does what and when.

Knowledge work, work that is typically performed by designers and engineers, can be complex to perform, manage and plan for. This makes the plan of most types of knowledge work difficult to visualize or and "hard to see". Wall-based visual planning has helped many companies to increase the visibility of knowledge work in a way that is simple to use, teach, implement and understand. As such, the methodology of visual planning has brought the ability to create flow in knowledge work by visualizing bottlenecks, complexities and interactions between individual tasks and joint deliverables. We (the authors of this paper) started out the foundational research of this work by exploring means to identify the trade-off between physical wall-based methods and various digital counterparts. In that process we did not identify simple and easy to use applications available, that supported the specific methodology used by the companies and engineering teams, and hence started to digitalize company specific wall-based methods, to counter multi-site problems, for evaluation purpose and eventually discovered approaches to further improve digital work practices, increase efficiency beyond the physical (or digital boards) through focus on synchronization, transparency and facilitated communication.

This was the beginning, and software prototypes being used and evaluated by industry, that eventually became a company that is now marketing solutions for different types of project and product development. This paper contains the Yolean story, reflecting over the usage of a commercial offering as the main vehicle for dissemination of research results within the domain of design science. This paper will present some of the challenges involved, and the positive effect we have seen in being able to attain large volume of first hand data through your own software being run in a real engineering context.

\section{METHODOLOGY}

This paper does not follow the traditional approach of gathering empiric data, analyse the result and concluding the results. This paper is based on the experience of the authors themselves initiating and running a research-based start-up primarily over the years 2012-2020. As researchers, doing research on your own work this could probably fall into the classification of action research, and participatory research (Robson 2002). This presentation aims toward full transparency of the setting and the narrative of the start-up story, but since it was not from the beginning set up as a research project the methodology applied is not easily presented or replicated. Still, it is possible to state a research question in order to guide the presentation in this paper:

What can scientists with a background in design science expect when choosing a commercially scalable offer (typically a SaaS business model) as carrier for a wider dissemination of their research?

With this question we will for the target audience "Scientists with a background in design science" do our best to present our experiences when selecting a "commercially scalable offer". The part relating to commercially scalable is key to this presentation as this makes this approach quite uncommon within design science. It is very common (and hence probably easier to get started) to offer your knowledge as a non-scalable service e.g., a consultancy service, rather than a fully scalable approach, such as a cloudbased software. Further, the question in itself conditions success in building and creating a scalable product, a product that can be sold with limited efforts, typically with little researcher/founder involvement. In our case this has meant a SaaS (Software as a Service) based approach, but other business models are viable. (In all respect writing a book or a paper could be considered a scalable approach for knowledge dissemination, and there are of course many good examples of that, however this approach tends not to get the industrial impact and continuous awareness as a software.)

This research question has for obvious reasons, been designed in retrospect, the primary intent of the commercialisation being transferring knowledge to industry and creating a viable business over time, i.e. not to perform research on that approach. Evaluating scalability indicates that the case company 
has gone through the start-up and transition phases (Picken 2017), being (at least) in the early scalable phase. This paper is based on the case of our research process that eventually resulted in the establishment of a software company. This is the single case study. Reflecting over the different stages of the DRM methodology, the development of the product (software) and company in itself indicates a prescriptive research study. Doing the follow up and evaluation of this research since beginning in 2012 we have also had the opportunity to do Descriptive II research (Blessing and Chakrabarti 2009).

As can be expected from this approach, the results and conclusions are likely to contain biases by the fact that the authors also are the object of study, hence observing and studying our own actions can probably not be anything else than biased. However, it is our sincere approach to be as objective as is possible. The scope of this paper is to share our experiences in a way that make them useful for the wider research community in design science. The goal is to present one reference point for those considering undertaking a similar endeavour by putting their research results to the test of trying to affect a wider base of practitioners through software (scalable) product (and not e.g., a consultancy) to increase the reach of the research results without the researcher having to be there to guide the application.

For full transparency the original organisational responsibilities of the authors are presented here: The researchers currently work as CEO and chairman, within the organisation. The CEO position is a fulltime position within the company, while the chairman position is not. The CEO and has a background with a MSc in mechanical engineering and a PhD in Product Development / Knowledge management. The chairman has a MSc in Electrical Engineering and a PhD in Product Development / Information management, currently working full time as a Professor. The third founder joined the team formally in 2012 when the research project leading up to the foundation of the company was initiated. The third founder has a master's degree in software engineering, was at the time running his own software startup company with experiences as a programmer from several large organisations.

\section{SCALING RESEARCH IN DESIGN}

The start-up scene of the modern the start-up world is a research field of itself. It includes how companies are maturing from initial idea towards a scalable product offering (e.g. (Picken 2017), the general principles of how modern B2B and B2C start-ups work to identify, test and validate ideas (Ries 2011) and how SaaS businesses are operating and valued (Churakova, Mikhramova et al. 2010). There are many similarities in how businesses are designed to how products are designed, the general principles of ideation and assessing outcomes applies.

\subsection{Development in the research phase}

Project Vis-IT (Visualisation and IT in Product and Production Development) was the name of the research project funded in 2012 by the Swedish Agency for Innovation Systems (VINNOVA). As it was funded from a research program targeting the automotive industry, it was led by AB Volvo. The main research partner was Chalmers University of Technology, and the industry partners were $A B$ Volvo, Autoliv, Dentsply and Toyota Material Handling. Industry (using the prototypes in actual product development projects) was set up to be the lab environment, where experiments were done, and solutions calibrated with design and manufacturing engineers. The challenge initially investigated was why so many IT systems fail to meet user needs. Initially the success of the Lean production paradigm was investigated together with newer Internet and startup phenomena and approaches (such as the lean startup methodology).

During the research project Vis-IT, from 2012, and till concluding the Vis-IT research project in 2015, Autoliv has been one of the major collaboration partners regarding the development of the digital visual planning system. Since the start Autoliv have had about 150 concurrent users of the system, primarily in Vårgårda, Sweden but also in other parts of Europe.

\subsection{Development in the commercial phase}

A key development partner from 2015 and forward has been Volvo Cars Global Customer Service (GCS). This division is responsible for aftermarket products and warranty claims of Volvo Cars worldwide. The organization has been working with visual planning since 2007, when the methodology was introduced by the current management to improve communication and quality of 
Volvo Cars aftermarket services. Currently several more departments at Volvo Cars are involved in the Visual Planning implementation involving at its peak more than 500 users within the organization.

"The implementation has led to that we now can work just as effectively in global teams as in local teams" said the implementation leader at Volvo Cars in 2017.

Starting in 2016 NCC has been a key development partner creating a new branch of Visual Planning support for the construction industry. The basic software has been configured to better support the challenges of the construction industry, both in the design and in the construction phases. Yolean currently supports over 50 projects within the construction industry and has been used in over 150 projects where the largest is the extension of Queen Silvia's Children's Hospital under construction in Göteborg. On a weekly basis more than 1000 people in the construction industry interact and rely on planning boards from Yolean for their daily work in both design and construction phases. Currently the software is being used predominantly in Sweden and Germany. Figure 1 shows Yolean in a construction setting running at a big screen on the construction site.

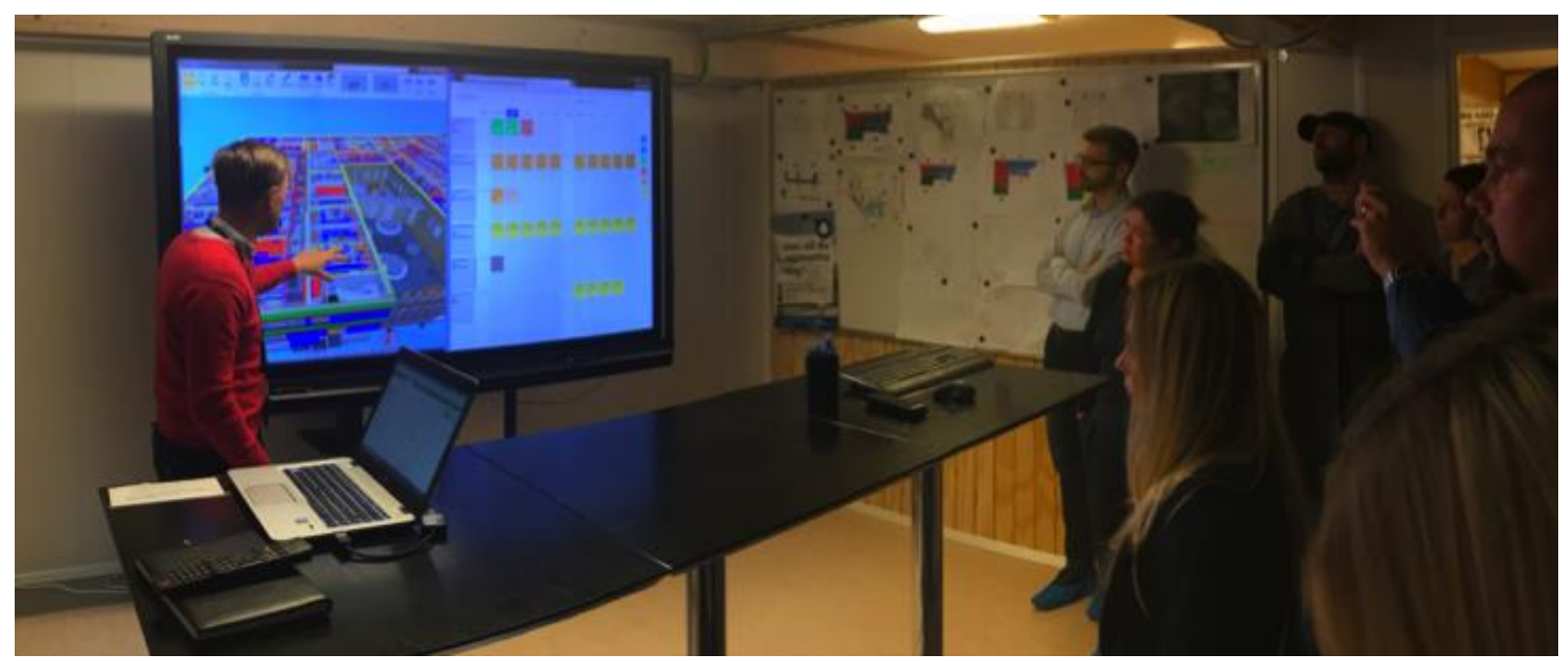

Figure 1. In 2016, work to support construction design and production phases was initiated in collaboration with NCC and the Queen Silvias Childrens Hospital construction project.

\section{DISCUSSION: THE STORY OF THE START-UP}

\subsection{Identifying the research challenge}

As initially stated in the introduction product development companies rely on production and development in a multitude of sites around the globe, to save costs and to enable advantages in local markets by being close to the customer and to offer engineering and availability around the clock in several time-zones. However, globalization has a cost where cultural barriers, communication barriers hinder development and cause miscommunication, delays, and increased cost. In product developing organisations, this can induce an unnecessary high cost, in both economical and human losses.

Lean product development has introduced a number of projects and development methodologies that encourages direct communication and that decreases miscommunication, however the lean paradigm focuses on personal communication and by using physical visual aids such as Pulse and Visual Planning boards (Lindlof and Soderberg 2011). A problem is that information is difficult to share across sites but also that information is often lost which hinders information exchange and learning. We chose to call this "in time" communication (units that are not co- located), and communication "over time" (when decisions and planning cannot be made synchronous) similar to e.g. Li et. al. (2018).

In parallel, IT support tools can be said to solve both "in time" and "over time" issues but they are not as visual and appropriate to support the meeting structure as the lean meetings are.

A question that you often ask yourself as a researcher and entrepreneur is that: Someone must have tested this before and solved the problem? in this case the problem of co-planning. - Apparently no. On the market there existed a whole lot of project management software, digital whiteboards and of course traditional (digital) product and project management systems. There was in principle two 
categories of systems available: (1) a digital whiteboard - This category of companies had seen the problem of writing or drawing on a whiteboard (sometimes even placing notes on the whiteboard) as the main problem. If this was the problem, then it was to be solved with a digital whiteboard - easy right? The problem was (as we regarded it) that the whiteboard was not the problem. In Lean there is an expression that says "go to Gemba" meaning to investigate the source, understand the real problem (Liker 2003). These suppliers apparently where not Lean (or just wanted to sell and market a digital whiteboard). (2) The second category of software could be even worse and was also the more common one; IT-companies showing off their old software system with a couple of tweaks making it "more lean" or "enabled for lean (or agile)". This actually does not help in any way; in most cases it seems to prolong the problem and has the potential of killing future lean and agile initiatives.

\subsection{Demonstrating prototypes in industry}

In the Vis-IT project we set out to revolutionize and modernize the way IT-systems are used at large industrial companies. To do so, we decided to either test an idea or discard it, in our previous experience, as researches we had done a lot of presenting, workshopping and discussing ideas in large forums, and it never resulted in a whole lot of valuable information.

To be effective in our scientific approach to test all of our ideas we need to design the experiment small enough, but still representative enough to be tested. The principles to find a good balance was: Test it in a real industrial setting: A workshop or a game is fine, but it is first when people use it for real that we can see that it works. Test an absolute minimum "thin slice" of the product: value is often generated by a small portion of the product, lets focus on that. Continue to use the product forever: if the test is successful, continue to build on it and document learning's. One of the guiding principles was the one of the Lean start-up (Ries 2011), focus on learning cycles and feedback from users. Figure 2 illustrates how mock-ups and quickly developed prototypes where designed and used within the research project to gain quick and almost instant feedback from users.
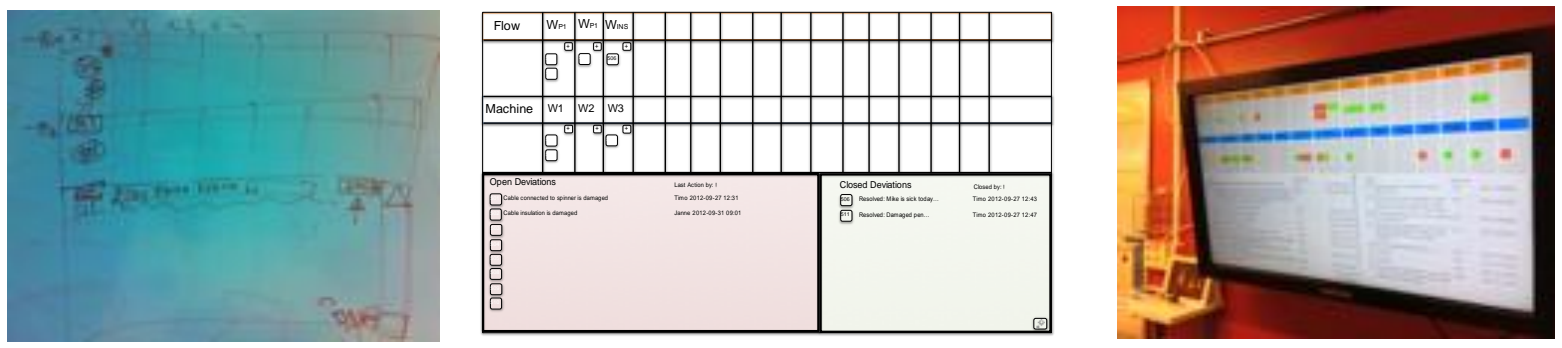

Figure 2. Process applied to develop software prototypes in 2012, (Whiteboard sketch, PowerPoint mock-up and Web application. (2 weeks of development time for prototype)

\subsection{Setting up a start-up company}

In order to assure the continuous delivery of service and support of the research prototypes Yolean $A B$ was incorporated in the beginning of 2014. The initial product portfolio consisted of the tools developed in conjunction with the research project, Visual Planning, Pulse, and Checksheets. Visual Planning has however become the main commercial success with over 20 customers mainly in the manufacturing industry and construction industry. One start-up advisor told us that creating a start-up company is not the end of the process of bringing your research to broader use... it is the start, and as such it is not really worth anything. A few researchers had approached him with the mindset of that now everything (the research) is finished, and you (the advisor) just have to find a few students to program this into an app. I guess we also in the beginning of 2014 had a similar (or maybe not so naïve) approach to the businessbuilding side of running a start-up. But starting the company is the start... it is definitely not the end, and as we will discuss further it is not really the end of the research but more of entering a new phase of your research now being partnered with start-up business. Figure 3 illustrates this beginning, as we now got real users using the application every day... so far (in December 2020) it has been running constantly and consistently for 2556 days (with 1 day of downtime in early 2013 due to a miscommunication with internal IT department). 


\subsection{Developing and maintaining the commercial product vs research prototypes}

The transition from developing prototypes, testing and evaluating them, which is common practice in the research society to move to a commercial offering of products that should work for users that have not been taking part in the development is challenging (for researchers), and this is where much research dies to never be implemented to a large audience, often referred to as the valley of death for start-up companies (Salamzadeh and Kawamorita Kesim 2015).

Key for a commercial offering is to keep the interest of the users beyond the point of research and to expand. A part of this is the continuous development of the software (which is no longer a prototype but has regular users) and to maintain and update as the underlying components are modified, changed or pulled. You get to know how many updates, and inconsistencies there are between web-browsers and how they work with or against the standards, when you run a SaaS company.

A new challenge presented to a product in the marketplace is also that you now have an infinite number of tasks to do and you need to prioritize based on the customer needs. Not so much the research application and the research need. When you get enthusiastic users, you also tend to get a lot of suggestions for how to improve the software, with 10 users it is manageable, with more users it becomes a tedious process where you possibly cannot help all users to get what they want fast.

A typical example of this evolution is that you cannot test as much as you did before. The core software/product offer takes a life of itself and you have to take into the consideration what existing customers would need, what is plausible given the legacy and decisions taken in the past and make sure that any new functionality will not screw up anything that apparently worked in the past and may be appreciated by silent users (who do not give you feedback since they like the product as it is).

In practice Yolean has continued development together with a few core users and customers. The major development during the past years has been the entry into the construction industry. Even though the base of the software is the same, from the user perspective it is a completely different product, with new user needs, processes and visualizations.

As the software matures, robustness, stability and compliance take a large portion of the resources, resources that are at least 10-fold as large as they were during the research period (2012-2014).

When starting a research project (with external funding) you have often already agreed on with your partners (potential client) of what you should do. Sometimes you encounter problems and need to change direction, however selling a product to a large organisation is something completely different than setting up a research project. You do expect long lead times, but you have not expected the lead times you get. Sometimes it seems to be all clear and then 3 months into the project the sponsor approaches you that they cannot pay the invoice since this was not run properly through the ITdepartment. At this point, some of our larger customers still regards our software as a prototype and treats it as a special case. There is a lot of creativity regarding how you should frame your product and service, both on the customer side, and on our side. It requires flexibility and the possibility to work for long times without being paid.
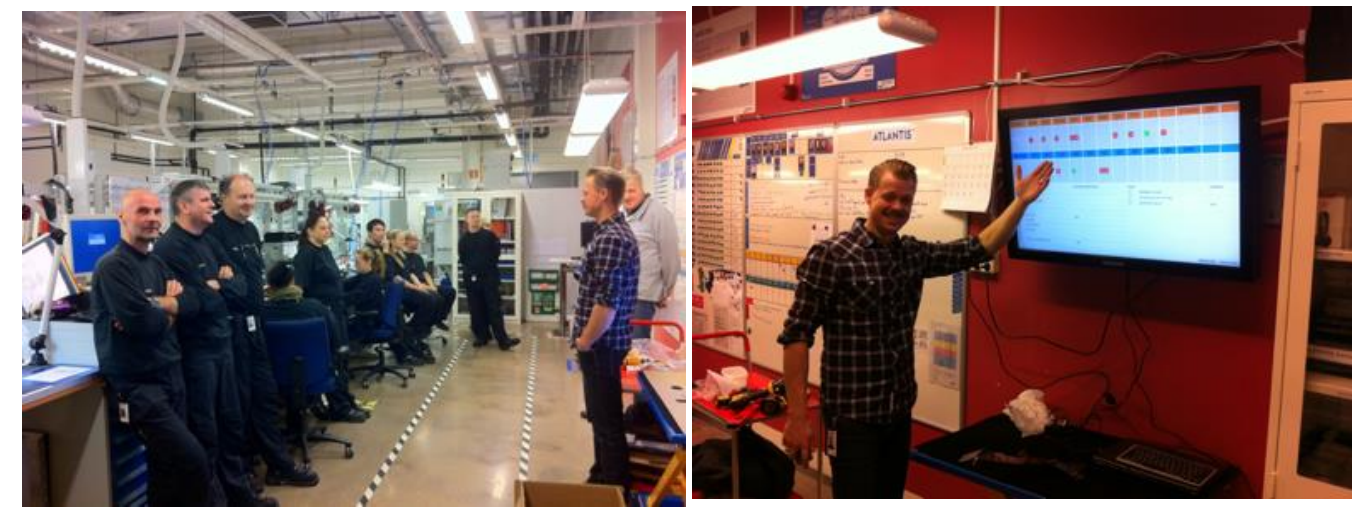

Figure 3. First prototype launched at Dentsply in 2012, (the updated software is still in use)

\subsection{Acquiring, onboarding and maintaining practitioners}

There is a fine line where research stops, and implementation/commercialisation takes over. The shift is gradual and can be experienced as an increased amount of administration without adding to a lot of new knowledge (relevant for the research). The first time you train users in the software and the 
methodology it comes with a lot of new learnings and experiences (you can write a research paper about it!), the 10th time you do the same thing there is not a lot of new experiences made (Figure 4 showing a typical training event at a customer site). We used to say that a good measure of how well your research is implemented can be measured in the amount of time you spend on administration, user support trying to resolve non-research related issues (bugs, user-support, feedback etc.). However, with research results being implemented, in a SaaS software, there are a lot of positive benefits for research (and product development). Now it is possible to track users, build statistics and learn from quantitative data that is being collected automatically and without any extra steps from the researcher. It is all there, a big automatic data collection machine especially if you set up your business that way and collect data in a way that is also approved for research purposes (GDPR, research ethics etc.).

To make great research you need data to analyse, however, to make a start-up work you need new customers. There is synergy, but it is definitely not the same approach. So how do Yolean work to attract and maintain customers? Not so much innovation here, and I guess this is where we as researchers can learn a lot from the rest of the start-up world and existing businesses. We used to think that if we publish and maintain a website and show up for conferences and presentations the practitioners will act as rational agents and adopt the method and the software based on its merits alone. This is true for the very "aggressive" customers that are out there looking for exactly what you have to offer... but not for most customers. It is easy to believe that if you build it, the users will eventually come. And maybe they will, most probably the will not. Though we expected that practitioners' decisions to adopt our product can be based on emotions as well as rationality it was challenging for someone with a strictly scientific background to adapt to this fact. Equally challenging is the advent of other factors that have nothing to do with neither the merits of the scientific argument for the product nor the emotional perceptions of the product. The influence of other stakeholders such as IT departments, luck of running into a stakeholder who "gets" the product and acts as champion or poor luck of internal reorganisations happening that render your champions to lose internal influence. It is hard to "prepare" for some of these factors but they can negatively influence the success (or at least the lead time) for getting the product (and with it your research results) widely used.

This is where it helps off to involve an external party (or people) like a university-based venture firm. You as a researcher have developed a methodology based on research. You have even managed to build the product, and as we did, managed to sell it to a couple of very large companies. However, we have no experiences in scaling, or selling to a lot of companies. The Yolean approach has, to this point been focused on serving the customers we have, and the ones that are interested enough to contact us and talk to us. However, the next step is to scale. This is where we will be able to build a mass market product. Have you ever tried to explain your research to someone that have no idea about what you are doing in a few catchphrases on a website or in a video clip? And then persuade them to pay for it? Even risk their future reputation for the sake of spreading your research. It does not matter if you can convince one person in an organization to buy your research. You have to help that individual convince his manager to put time into it. Not only their manager, but maybe a full board of different managers.

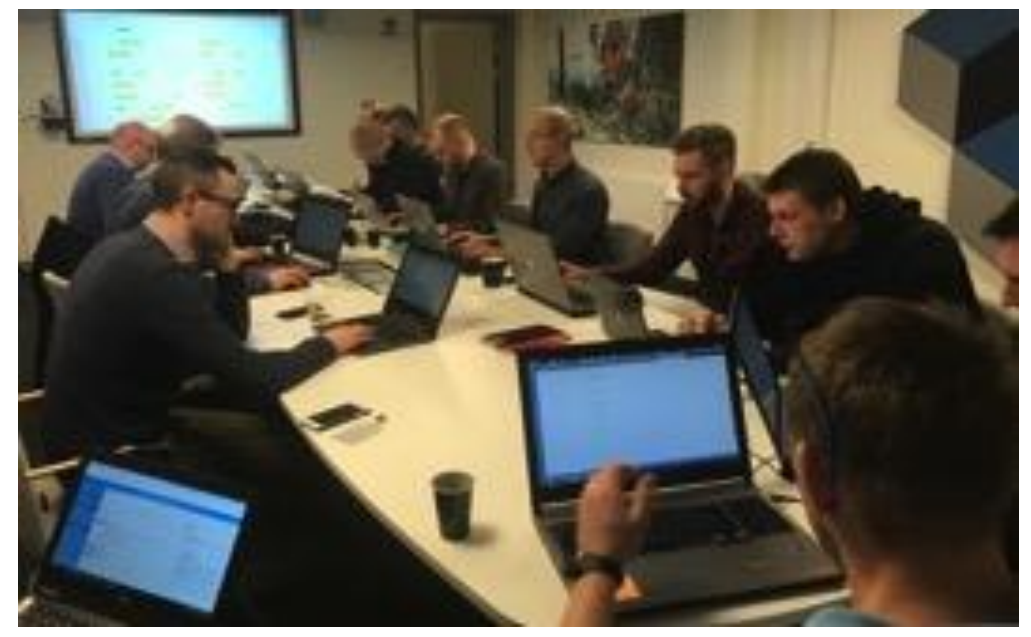

Figure 4. Training in Visual Planning Software, at Husqvarna (Spring 2019) 


\section{IMPACT FROM RESEARCH AND COMMERCIAL IMPLEMENTATION}

To create a company which markets a software, is not easy and it is in itself not a guarantee for impact. The impact comes with what users can do, and achieve, with these new tools in their hands, that they could not previously do or do with less efficiency. This is probably also the most difficult measure to obtain. How can we prove that companies actually gain benefits from using the software in comparison to not using it? We always have to compare with historical data from projects doing similar things, but not the same. The factors we want to investigate cannot be isolated in relation to all other improvement projects and changes that continuously take place within companies.

As researchers we also have to deal with the risk of being biased of seeing things that are not there, or as described in the Descriptive Study-II research study ((Blessing and Chakrabarti 2009): it is interventional and incorporates a high risk of research bias since it aims to evaluate whether the introduction of a support improves the existing situation. Pointing towards growth, and new users, does not fulfil such a level of verification/validation as it cannot be traced back to what, specifically (given research questions or hypothesis) that led to the growth and improvement. Yolean currently tends to attract new customers from businesses with a lower degree of digitalization maturity than its initial customers. The easiness of use is often highlighted by these customers, also the fact that it can be used very quickly without educating software experts. The software is attributed as a system developed for the user, and in line with Lean (and agile) development philosophies that the customer is already using. With that stated, there are also hard facts. As mentioned by customer IT departments, the digital solution makes it possible to scale quicker (as compared to physical methodology): it is easier to set up in different countries, different departments, and availability is instant.

In the construction industry, we have shown that by supporting the correct communication and interfaces, lead-times for building advanced structures can potentially be reduced from 6 to 2 months (in practice the reduction at the documented case was from 6 to 2,5 months due to deviations in the design phase). The larger part of the reduction ( 2 months) was attributed to the methodology by asking the right question and documenting answers accordingly. However, 1 month was directly attributed to the superior way of visualizing relations in a digital system, as compared to a physical system. This project was conducted in Germany during the fall of 2018(1). In addition, there is anecdotal evidence from project managers in the design phases who claim that they weekly spend 4-8 hours less on administration related to communication in teams. Meaning that they don't need to manage email threads to make sure the right information about decisions made or concerns raised is forwarded to the right team members in each specific issue).

Further evidence in the construction industry shows a potential for greater impact, than a software tool alone, is to establish collaboration with consultancies specialized in lean construction. Traditionally it has taken a week to get a construction project up and running during the initial phases of the project. However, thanks to the digitalization and standardization of the methodology it is now possible to scale quicker. A German Lean construction consultancy show that their own capacity has increased 3 times, thanks to the possibilities of Yolean, this is attributed towards less travel, higher degree of standardization, and support built into the software. In times of Covid19 it is also a survival strategy for consultancies and service providers in the construction industry.

\section{CONCLUDING REMARKS AND RECOMENDATIONS}

In this chapter we summarise the findings of the paper, and tries to answer the research question (presented in the methodology chapter); What can scientists with a background in design science expect when choosing a commercially scalable offer (typically a SaaS business model) as carrier for a wider dissemination of their research? With this question we aimed to identify what our best advice for any researcher, with in our field, should reflect over when starting up their business (and during the first five years), what to expect and hopefully how to overcome them, more quickly than we did. Research results in the domain of design science are most likely to render B2B products. That would be a natural occurrence for us as studying designers and their work has been in focus, and not the designs or products. Our general recommendations after writing this paper are:

(1) https://reif-bau.de/datengetriebene-prozessoptimierung-mit-digital-lean/ (In German: Accessed 202012-11) 
- Don't rely on rational arguments as carriers of the product message. As researchers (and engineers) we may look too much on the data. Selling is more of persuasion rather than finding all rational arguments. It is often only one thing or argument that tips the scale in your favour.

- Expect long lead times in the decision-making processes of customers, especially in the beginning of your approach, and especially when the companies are large. Make your endeavour resilient to such lead times (one of our first customers took over 3 years until they paid their first invoice).

- Secure some form of investment or similar funds that can take you through low cash flow periods while you are waiting for internal decision-making processes. Can you make the overlap between research and commercialisation bridge the valley of death, i.e. prolonging the research further into the commercialisation phase? Does the university have specific seed funds for researchers?

- Initiate as many parallel discussions as possible. Do not rely on only one company or contact and wait for their decision processes to go through (as you are likely to run out of cash and patience while waiting). You have to kiss a lot of frogs until you find a prince... and that romance can be short when you realise that the prince is broke or do not have access to any of the king's treasure chest.

- Your first contact person in a new company is most likely to be the most positive person to your product. Anyone you meet after that is likely to be moderately impressed (or completely unimpressed) by your product. Therefore, you need to help your champion with arguments to spread your message internally. When making the material (PowerPoints, guidelines, videos etc). It will require a thousand yes to get your software up and running, but only one no to get it stopped... you will often even not get a no, more likely a "not right now" or "we have just gone through a reorganisation and we need to consolidate our efforts... let's have a look at this in 6 months".

Finally, at some stage in this journey you have to decide if you want to be an entrepreneur or a researcher. If you have a tendency to spend a lot of time to reformat and rewrite your research papers, you will not have time left to convince users and potential customers to use your software (and hence not get the feedback needed to improve it). One of us decided to jump on the ship and the other one wrote this paper.

\section{WEBSITES}

https://reif-bau.de/datengetriebene-prozessoptimierung-mit-digital-lean/ (In German: Accessed 202012-11)

\section{ACKNOWLEDGMENTS}

The authors would like to acknowledge the support of the Wingquist Laboratory and the Area of Advance Production at Chalmers. The research has been supported by the Swedish Governmental Agency for Innovation Systems (VINNOVA).

\section{REFERENCES}

Blessing, L. T. and A. Chakrabarti (2009). DRM: A Design Research Methodology, Springer.

Churakova, I., R. Mikhramova and I. F. Gielen (2010). "Software as a service: Study and analysis of saas business model and innovation ecosystems." Universiteit Gent: 103

Li, D., Paulin, D., Fast-Berglund, Å., Gullander, P., \& Bligård, L. O. (2018, November). Supporting individual needs for intra-organisational knowledge sharing activities in pre-industry 4.0 SMEs. In 15th International Conference on Intellectual Capital, Knowledge Management and Organisational Learning, ICICKM 2018 (pp. 160-170).

Lindlof, L. and B. Soderberg (2011). "Pros and cons of lean visual planning: experiences from four product development organisations.” International Journal of Technology Intelligence and Planning 7(3): 269-279.

Liker, J. (2003). The Toyota Way: 14 Management Principles from the World's Greatest Manufacturer, McGraw-Hil.

Picken, J. C. (2017). "From startup to scalable enterprise: Laying the foundation.” Business Horizons 60(5): 587-595.

Ries, E. (2011). The lean startup: How today's entrepreneurs use continuous innovation to create radically successful businesses, Crown Books.

Robson, C. (2002). Real World Research. Oxford, UK, Blackwell Publishers.

Salamzadeh, A. and H. Kawamorita Kesim (2015). Startup companies: Life cycle and challenges. 4th International conference on employment, education and entrepreneurship (EEE), Belgrade, Serbia. 


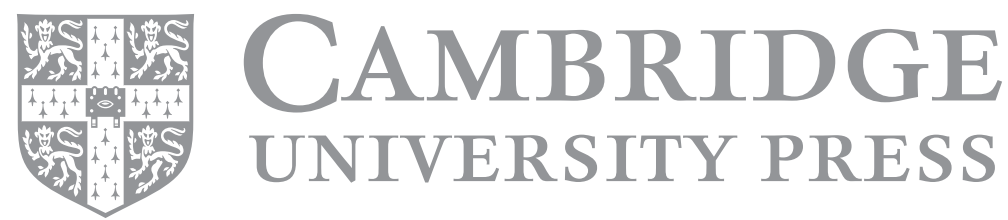

